\title{
Comparative lipid profiling of murine and human atherosclerotic plaques using high-resolution MALDI MSI
}

\author{
Pegah Khamehgir-Silz ${ }^{1,2} \cdot$ Stefanie Gerbig ${ }^{1} \cdot$ Nadine Volk $^{3,4} \cdot$ Sabine Schulz ${ }^{1}$ Bernhard Spengler ${ }^{1} \cdot$ Markus Hecker $^{2}$. \\ Andreas H. Wagner ${ }^{2}$ (D)
}

Received: 19 October 2021 / Revised: 19 October 2021 / Accepted: 6 November 2021 / Published online: 19 November 2021

(C) The Author(s) 2021

\begin{abstract}
The distribution of atherosclerotic lesions in the aorta and its branches of ApoE knockout (ApoE ${ }^{-/-}$) mice is like that of patients with atherosclerosis. By using high-resolution MALDI mass spectrometry imaging (MSI), we aimed at characterizing universally applicable physiological biomarkers by comparing the murine lipid marker profile with that of human atherosclerotic arteries. Therefore, the aorta or carotid artery of male $\mathrm{ApoE}^{-/-}$mice at different ages, human arteries with documented atherosclerotic changes originated from amputated limbs, and corresponding controls were analysed. Obtained data were subjected to multivariate statistical analysis to identify potential biomarkers. Thirty-one $\mathrm{m} / \mathrm{z}$ values corresponding to individual lipid species of cholesterol esters, lysophosphatidylcholines, lysophosphatidylethanolamines, and cholesterol derivatives were found to be specific in aortic atherosclerotic plaques of old $\mathrm{ApoE}^{-/-}$mice. The lipid composition at related vessel positions of young $\mathrm{ApoE}^{-/-}$mice was more comparable with wild-type mice. Twenty-six $\mathrm{m} / \mathrm{z}$ values of the murine lipid markers were found in human atherosclerotic peripheral arteries but also control vessels and showed a more patientdependent diverse distribution. Extensive data analysis without marker preselection based on mouse data revealed lysophosphatidylcholine and glucosylated cholesterol species, the latter not being detected in the murine atherosclerotic tissue, as specific potential novel human atherosclerotic vessel markers. Despite the heterogeneous lipid profile of atherosclerotic peripheral arteries derived from human patients, we identified lipids specifically colocalized to atherosclerotic human tissue and plaques in $\mathrm{ApoE}^{-/-}$mice. These data highlight species-dependent differences in lipid profiles between peripheral artery disease and aortic atherosclerosis.
\end{abstract}

Keywords MALDI imaging $\cdot$ Atherosclerosis $\cdot$ Lipid profiling $\cdot$ Human $\cdot$ ApoE

Markus Hecker and Andreas H. Wagner contributed equally to this work.

Andreas H. Wagner

a.wagner@physiologie.uni-heidelberg.de

1 Institute of Inorganic and Analytical Chemistry, Justus Liebig University, Giessen, Germany

2 Department of Cardiovascular Physiology, Heidelberg University, Im Neuenheimer Feld 326, 69120 Heidelberg, Germany

3 Institute of Pathology, Heidelberg University Hospital, Heidelberg, Germany

4 Tissue Bank of the National Center for Tumor Diseases, Heidelberg, Germany

\section{Introduction}

Cardiovascular diseases (CVDs) are still the leading cause of all deaths worldwide [55]. Atherosclerosis is the major cause of CVD and is regarded as a chronic inflammatory disease of middle-sized and large conduit arteries [46]. Because of local hemodynamic alterations, particularly coronary arterial bifurcations are susceptible to atherosclerosis [38]. Atherosclerotic plaque development and rupture may be influenced by the lipid composition within plaques, resulting in thrombotic occlusions, which account for most life-threatening acute coronary syndromes [18]. During the process of plaque progression, the plaque contents may be regarded as surrogate markers of plaque status and risk of complications [33]. Lipids constitute a heterogeneous molecular class which is classified into eight categories by the Lipid MAPS consortium [12]. The in situ investigation of this molecular 
class by matrix-assisted laser desorption/ionization mass spectrometry imaging (MALDI MSI), first introduced in 1994 [50], enables identification and visualization of hundreds of lipid species with a label-free and non-targeted method directly from the tissue. Since then, instrumental advancements $[25,26]$ have made MALDI MSI a powerful tool for the investigation and visualization of lipids [14, 22], peptides [20], biomolecules and their metabolites, pharmaceuticals, and other xenobiotics [47] in biological samples.

In the context of atherosclerosis, recent studies use MSI as a novel strategy to visualize atherosclerotic plaque localization in the aorta of atherosclerotic mice such as LDL receptor knockout $\left(\mathrm{LDLR}^{--}\right)$fed a cholesterol-rich diet or apolipoprotein E knockout $\left(\mathrm{ApoE}^{--}\right)$mice [7, 31], and to evaluate treatment effects on plaque formation and remodelling of the complex lipid components [7]. These animal studies define several lipid markers for a deeper understanding of the causes and underlying mechanisms of plaque progression. Other recent studies analyse data from a few human samples, e.g., to illustrate the potential for imaging lipid biochemistry in human atherosclerosis [53]. Recently, a 2-dimensional (2D) and three-dimensional (3D) MALDI-MSI study identified plaque-specific lipids in $\mathrm{ApoE}^{-/-}$and $\mathrm{LDLR}^{-1-}$ mice [6]. In our study, we used MALDI MSI as a label-free and non-targeted method [45] for the direct comparison of murine and human atherosclerotic plaques to determine lipid markers for the differentiation of $\mathrm{ApoE}^{-/-}$from wild-type mice and for human atherosclerotic tissue samples with differences in progression and medication which, to the best of our knowledge, has not yet been performed.

\section{Material and methods}

\section{Materials}

Acetone (Uvasol®), trifluoroacetic acid (Uvasol $\left.{ }^{\circledR}\right)$, and 2,5-dihydroxybenzoic acid (DHB) were purchased from Merck KGaA (Darmstadt, Germany). Water (HPLC grade) was purchased from Sigma (Steinheim, Germany). Gelatine was purchased from VWR Chemicals (Leuven, Belgium).

\section{Murine tissue samples}

Inbred male $\mathrm{ApoE}^{-/-}$mice (B6.129P2-ApoE/tm1/Unc/J; stock No. 002052, The Jackson Laboratory, USA) and male wild-type (WT) control littermates were housed in the Interfaculty Biomedical Research Facility (IBF) of Heidelberg University under standard conditions with 12-h light and 12-h dark cycle. Water and chow were offered ad libitum. All animal experiments were performed with the permission of the local animal welfare committee (Regional Council
Karlsruhe, Germany, permission number G-229/19) and conformed to the guidelines from Directive 2010/63/EU of the European Parliament on the protection of animals used for scientific purposes or the current NIH guidelines. Young and old $\mathrm{ApoE}^{-1-}$ mice (age, 14-15 weeks, $n=2$, or 49-60 weeks, $n=4$ ) and WT mice (age, 15 weeks, $n=2$; 48-49 weeks $n=4$ ) were used in this study (Supplemental Table S1). After anesthetization, the mice were euthanized by exposure to carbon dioxide, and the aortic arch was perfused with phosphate buffer solution (PBS), excised, and processed for histological examination.

\section{Human tissue sample}

Human tissue samples were provided by the tissue bank of the National Center for Tumor Diseases (NCT, Heidelberg, Germany) following the regulations of the tissue bank and the approval of the ethics committee of Heidelberg University on research on humans. Written informed consent was obtained from each patient included in the study. The study protocol conforms to the ethical guidelines of the 1975 Declaration of Helsinki.

Serial $7-\mu \mathrm{m}$-thick cryosections were cut from vessel tissue samples embedded in 5\% gelatine in a cryostat from 8 subjects with diagnosed atherosclerotic changes (mean age \pm SEM, $63 \pm 14.8$ years) and 3 control subjects $(63 \pm 5.4$ years) without atherosclerotic changes. The tissue specimens originated from amputated limbs; surgical indications are indicated in Supplemental Table S2. Medication with HMG-CoA reductase inhibitors including the daily dose is also indicated in Supplemental Table S2.

\section{Immunofluorescence analysis}

Longitudinal or cross cryosections (10- $\mu$ m thickness) of the murine aorta or carotid artery were incubated at first with a blocking buffer (5\% donkey serum, \#017-000-121, Dianova, in PBS-T containing 0.05\% Triton-X-100) in a humidified chamber at room temperature for $1 \mathrm{~h}$. The primary endothelial cell marker antibody anti-CD31 (1:50, sc-18916; Santa Cruz Biotechnology, Germany) and the monocyte/macrophage marker antibody anti-F4/80 (1:100, MCA497GA, Bio-Rad Laboratories, Germany) were administered overnight at $4{ }^{\circ} \mathrm{C}$. The corresponding secondary antibodies (1:100, donkey anti-rat AlexaFluor 488 [712-546-150] and donkey anti-rat Dylight 549 [712-585-153]; Dianova, Germany) were subsequently incubated for $1 \mathrm{~h}$ at room temperature. In addition, the tissue sections were stained according to standard procedures for MAC387 immunopositive infiltrating macrophages (1:100, ab22506, Abcam, UK) and CD31 (1:100, M0823, Agilent Dako, USA) using donkey-anti-mouse cy3 [715-166-020] and donkey antimouse cy2 [715-225-150] as secondary antibodies (1:100, 
both from Dianova, Germany), respectively. Cell nuclei were stained with DAPI according to standard protocols. Mowiol 4-88 (Merck Millipore) was used as a mounting medium.

Atherosclerotic plaques were identified by haematoxylin and eosin (H\&E) staining according to standard protocols and/or using a Movat's pentachrome staining kit (Dianova, Germany) according to the manufacturer's instructions. Microscopy and visualization were performed using an Olympus Spinning Disc Confocal microscope and the Olympus Xcellence imaging software (Olympus Europa SE \& Co. KG, Hamburg, Germany).

\section{MALDI MS imaging}

For better sectioning, all tissue samples were embedded in a metal mold with 5\% gelatine by freezing [24]. Sections with a thickness of $10 \mu \mathrm{m}$ were mounted on a microscope glass slides (SuperFrost, Thermo Scientific Menzel Gläser) using a cryostat Microm HM550 (Thermo Fisher Scientific, Germany) at a temperature of $-21^{\circ} \mathrm{C}$ and stored at $-80^{\circ} \mathrm{C}$ until analysis. For analysis, tissues were defrosted in a desiccator, covered with $80 \mu \mathrm{L}$ of 2,5-dihydroxybenzoic acid $(30 \mathrm{mg} / \mathrm{mL}$ in acetone:water (1:1) with $0.1 \% \mathrm{TFA})$ in one passage with a flow rate of $5 \mu \mathrm{l} / \mathrm{min}$, a gas pressure of $1 \mathrm{bar}$, and a tracking speed of $350 \mathrm{U} / \mathrm{min}$ using an ultrafine matrix preparation sprayer (SMALDIPrep, TransMIT GmbH, Giessen, Germany). The samples were measured with an atmospheric-pressure MALDI imaging ion source (APSMALDI10 and AP-SMALDI5 AF, TransMIT GmbH, Giessen, Germany) coupled to an orbital trapping mass spectrometer (Q Exactive and Q Exactive HF, Thermo Fisher Scientific GmbH, Bremen, Germany) [45]. Measurements were performed in positive-ion mode with 30 laser pulses per pixel using a mass range of $m / z 300-1200$ and a mass resolution of $R=140,000$ or $R=240,000 @ \mathrm{~m} / z 200$. Internal mass calibration was achieved using the lock-mass feature of the orbital trapping mass spectrometer resulting in a mass accuracy of $\pm 3 \mathrm{ppm}$. Murine samples were measured with a spatial resolution (i.e., step size) of $7 \mu \mathrm{m}$. Depending on the region of interest, human tissue samples were measured with a spatial resolution between 5 and $15 \mu \mathrm{m}$ per pixel as described in detail in Supplemental Table 2. For lipid characterization on tissue, MS experiments were performed but since signal intensities of the detected markers were too low, the experiments were not successful.

\section{Data processing and statistical analysis}

Based on literature search [16, 28, 51], the lipid classes cholesterol esters (CE), lysophosphatidylcholines (LPC), lysophosphatidylethanolamines (LPE), and cholesterol derivatives $(\mathrm{CD})$ were chosen for this study because these lipid classes play a crucial role in atherosclerosis plaque development and progression. The generated MALDI MSI data, however, contains much more information, e.g., other lipid classes and smaller metabolites not considered in this study.

A list of 551 lipid species was composed and downloaded on September 5, 2017, from the LIPID MAPS database website. Exact $\mathrm{m} / \mathrm{z}$ values were calculated using different adducts $\left(\mathrm{H}^{+}, \mathrm{Na}^{+}, \mathrm{K}^{+}\right.$, and $\left.\mathrm{NH}_{4}^{+}\right)$for these species, and $\mathrm{MS}$ images were generated with a bin width of $\Delta(\mathrm{m} / \mathrm{z}) 0.01$ using MSiReader V09-1 [44]. MS images showing characteristic patterns of plaque distribution at aortic bifurcations were selected for further analysis. The $\mathrm{ApoE}^{-1-}$ mice tissue samples were compared to each other, and only those $\mathrm{m} / \mathrm{z}$ values which were found in all samples of $>40$-week-old mice and which showed no signal in the WT control samples were selected as potential markers. After calculating mass errors of potential markers using the in-house developed software package Mirion V3 [40], signals with a mass error of less than 3 ppm were selected. Human tissue samples were handled the same way with the difference that due to the lipid variability each measurement was considered individually. A more detailed description of the data analysis is given in the Supplementary Data. In addition, a list of oxidized lipid species [1, 8, 13, 19, 21, 27, 36, 42, 43] was compiled from literature and $\mathrm{m} / \mathrm{z}$ values were generated. From this list, only oxCE (18:2) and 9(S)-HODE CE were found in the measurement data set. Oxidized lipids were thus excluded from PCA because we superficially looked at some interesting oxidized lipids and did not perform an in-depth investigation in this regard.

For PCA of the murine tissue samples, intensities of the potential markers were exported and normalized to the total ion current (TIC) of each measurement. Intensities of nonselected signals were set to zero. The PCA was performed using the software package Perseus (version 1.4.1.3, Max Planck Institute of Biochemistry, Martinsried, Germany). The nonparametric Kruskal-Wallis test was used to determine if any of the intensity means significantly differed from each other by calculating $p$-values; $p$-values $<0.05$ were considered statistically significant.

All measurements performed on mice tissue samples $\left(\mathrm{ApoE}^{-/-}\right.$and WT) were carried out using equal measurement conditions (matrix preparation, pixel size, spot size, laser pulses, etc.). Under the given conditions, the MALDI-MSI data of the murine samples can be considered semi-quantitative.

Since the human tissue samples were measured with different spatial distributions, the intensities of the detected lipids were set to 1 , for lipids detected with low intensity to 0.5 , and for not detected lipids to 0 for the PCA analysis using the software package Perseus. The human tissues samples were divided into two groups (AT and control). Of all detected lipids, only those fulfilling the prerequisite, that 
a)

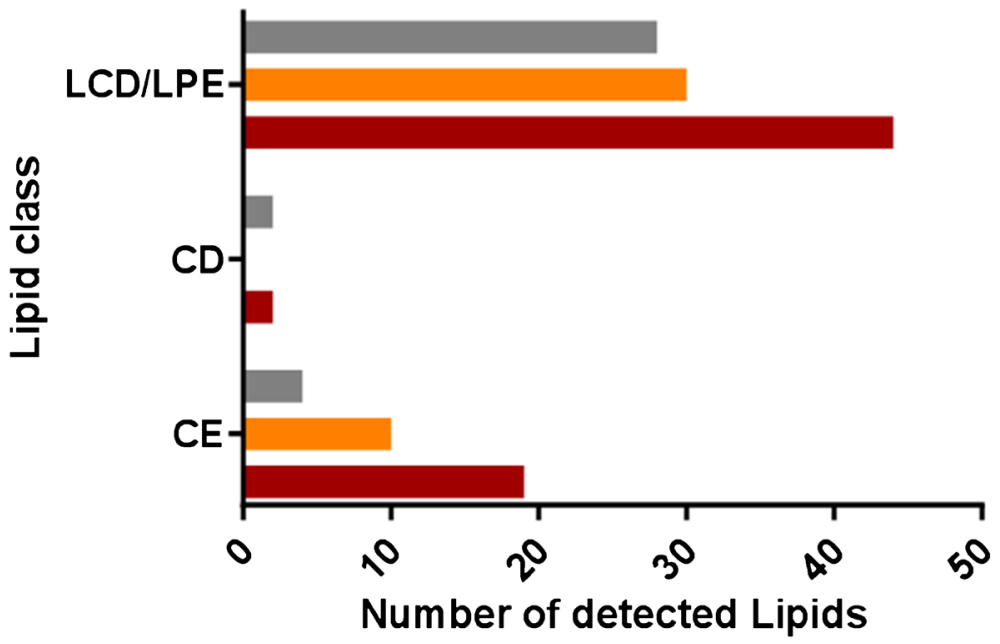

WT

ApoEyoung ApoEold b)

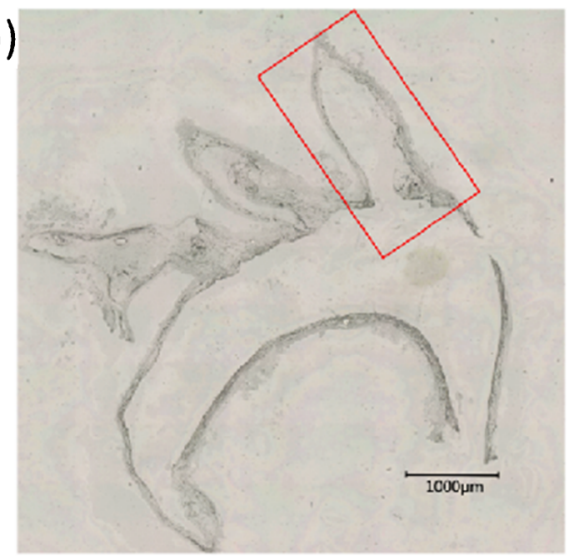

c)

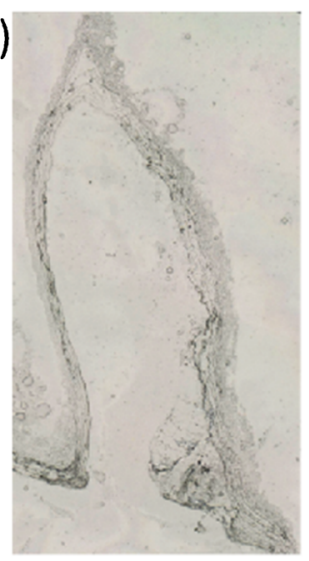

d)

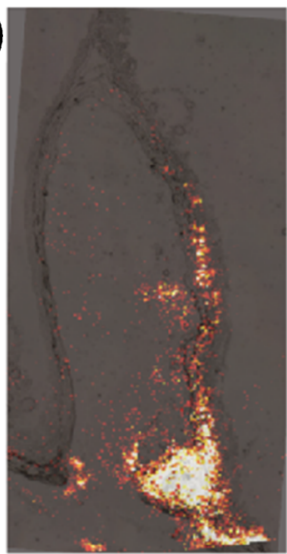

$\times 10^{3}$

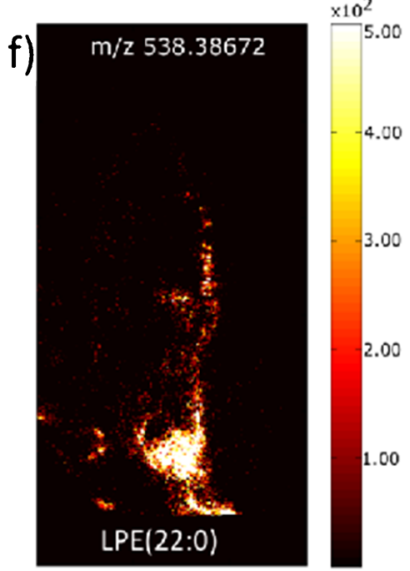

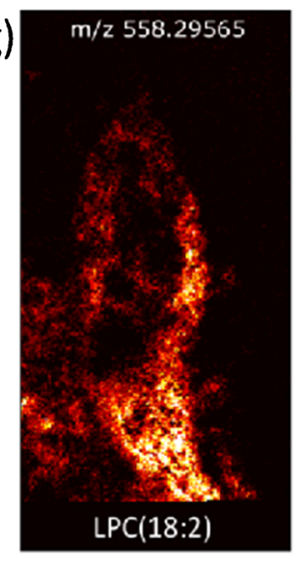

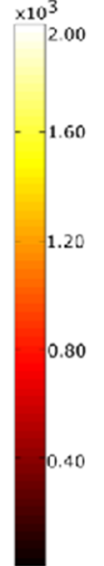

h)

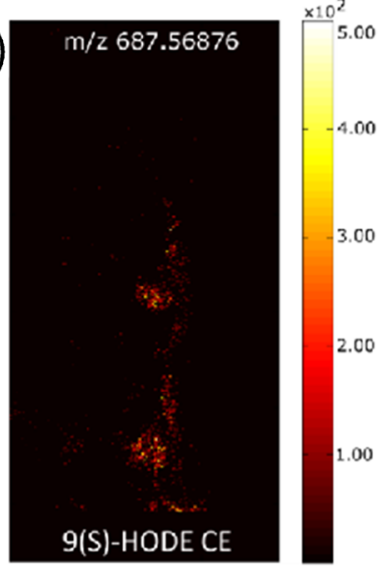

e)
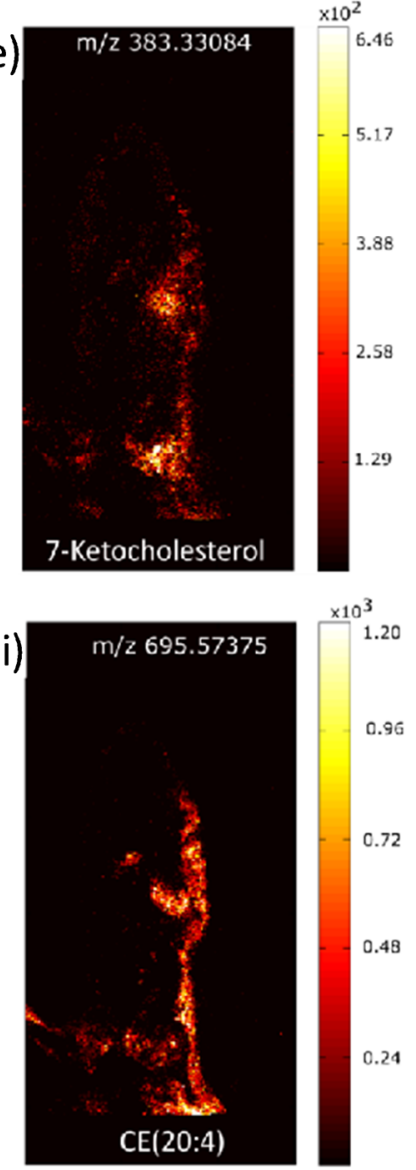

Fig. 1 MS imaging of atherosclerotic plaques in the aorta and its branches of ApoE mice. a Overall number of detected lipids in the lipid classes of cholesterol ester (CE), cholesterol derivatives (CD), and lysocholestrolderivatives (LCD)/lysophosphatidylethano-lamine (LPE). b Exemplary brightfield microscopy overview image of a cross-section of the aortic arch and its branches of an old ApoE knockout mouse (ApoE3, 49 weeks). The red square marks the left subclavian artery, which is shown enlarged in c. d Overlay of the optical image (c) and an MS image representing LPE(22:0) are shown in f. e-i MS images of the MALDI MSI measurement in positive-ion mode (pixel size $7 \mu \mathrm{m}, 200 \times 400$ pixels), presenting an example for the overall number of detected lipids shown in a 
$70 \%$ of the samples in one group need to have a value greater than 0 , were subjected to PCA. The $p$-values were calculated similarly to the mouse data.

\section{Results}

\section{Murine tissue samples}

The $\mathrm{ApoE}^{-1-}$ mouse as an established atherosclerosis model was first used to identify possible lipid markers for the subsequent evaluation of human atherosclerotic vessel samples. Atherosclerotic plaques were identified in the aorta on each tissue slide by H\&E and/or Movat's pentachrome staining accompanied by positive immunofluorescence staining for pro-inflammatory macrophages in the vessel wall (exemplified in Supplemental Figure S1). Within identified plaque areas, regions of interest (ROIs) were further subjected to mass spectrometry imaging analysis in the neighbouring sections.

A total number of 65 compounds from the compiled lipid list including adducts were found in the plaque tissue of the older $\mathrm{ApoE}^{-/-}$mice, 31 of which were exclusively found
Fig. 2 Representative lipids of lipid classes exclusively detected in old ApoE knockout mice and principal component analysis. a Statistical summary of the intensities normalized to the total ion current (TIC) for the indicated lipids in the arterial sections of old $\mathrm{ApoE}^{-/-}$ (49-60 weeks, $n=4$ ), young ApoE $^{-/-}(14-15$ weeks, $n=2)$, and WT (15-49 weeks, $n=6)$ mice. $* p<0.05$ vs. wild-type. b Principal component analysis of measured lipids shown in Supplemental Table S3 for WT and $\mathrm{ApoE}^{-/-}$mice. The lipid composition within the plaque areas of the young $\mathrm{ApoE}^{-/-}$ mice (ApoE5 and ApoE6) was largely comparable to that of the WT mice
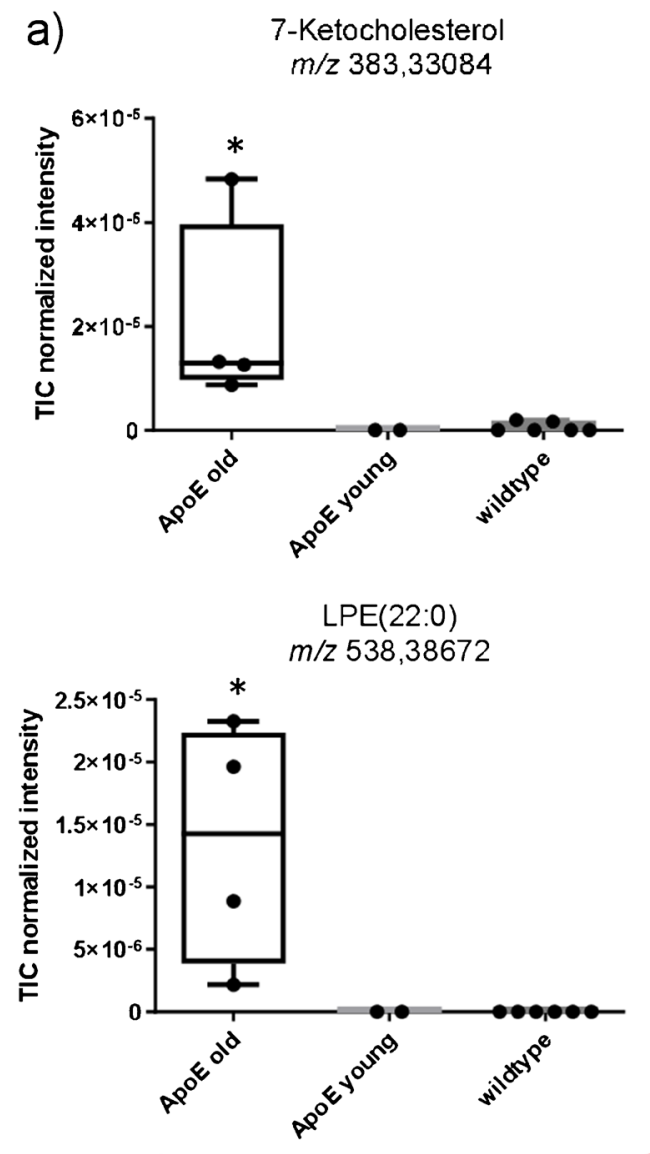

b)

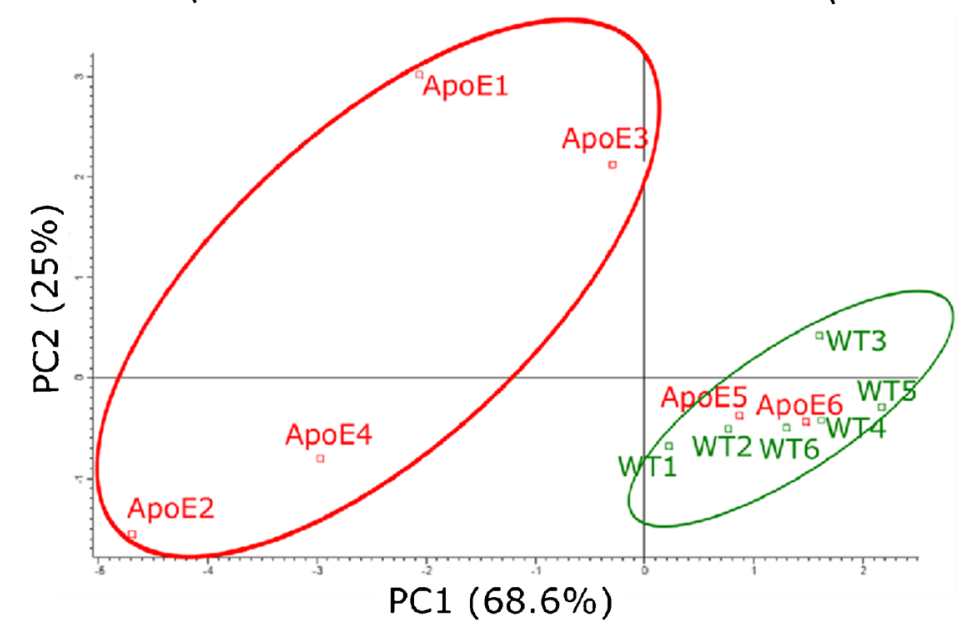

$\mathrm{CE}(20: 4)$ $\mathrm{m} / 2695,57375$

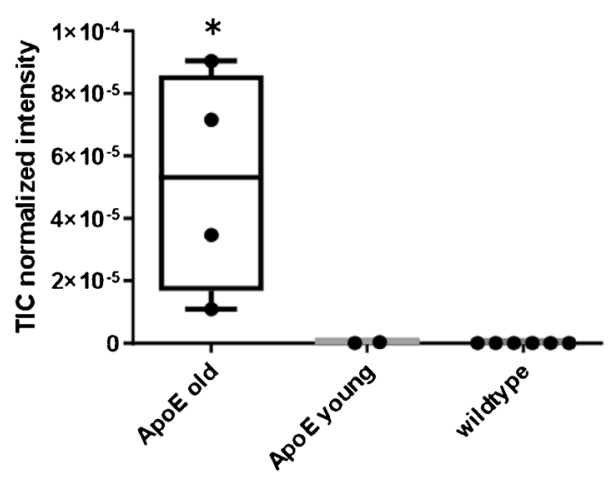

$\operatorname{LPC}(18: 2)$

$\mathrm{m} / \mathrm{z} 558,29565$

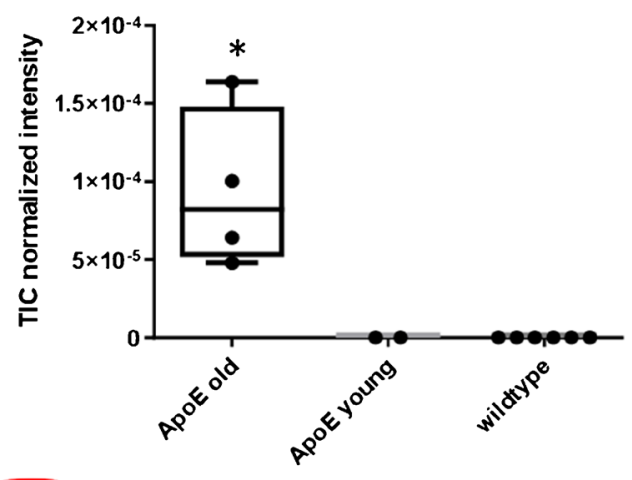



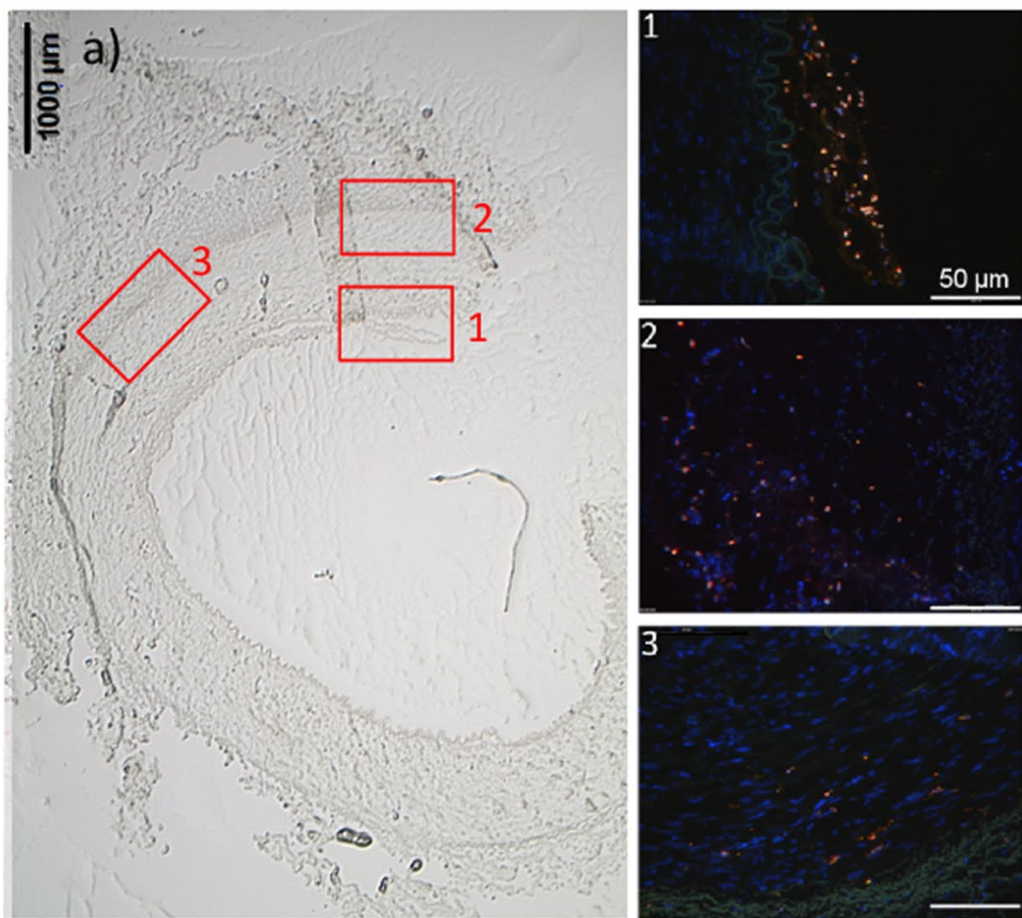

b)
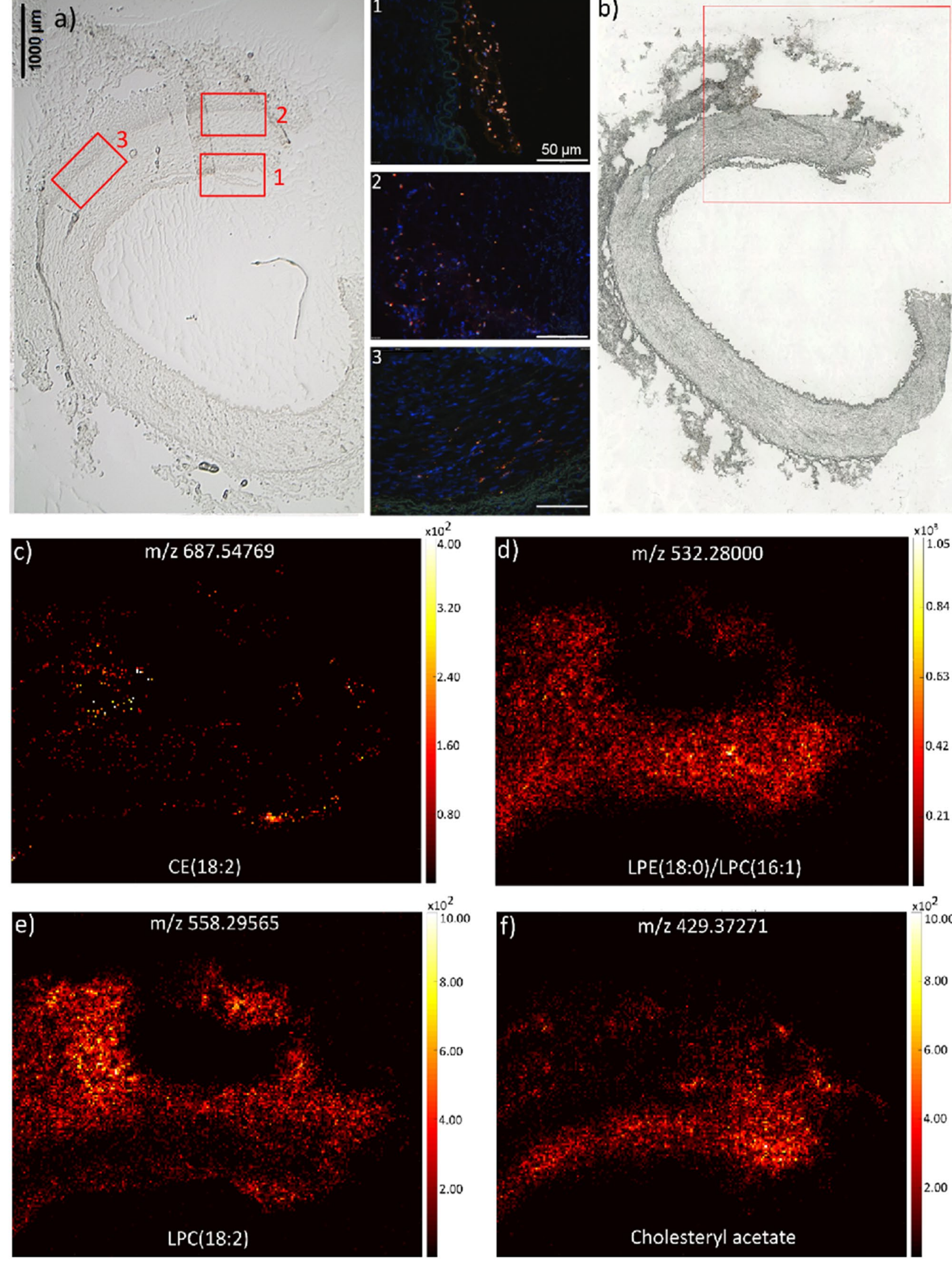

$\times 10^{2}$

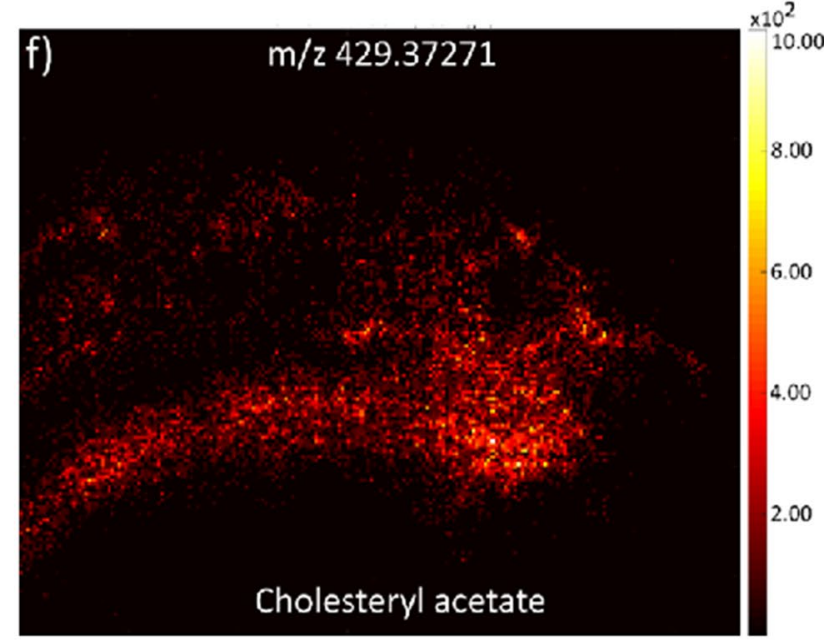


4Fig. 3 MS imaging of a human artery with atherosclerosis. a Exemplary image of a larger peripheral artery resected from the upper thigh (patient AT2), depicting a macrophage infiltrate (red fluorescence) into the atherosclerotic vessel wall (refer to insets 1-3, marked as red squares in the optical image). The blue fluorescence (DAPI) represents the nuclear counterstain. b An optical image of the tissue layer is shown and the area (red square), which was measured with MALDI MSI in positive-ion mode. The MS images (c-f) show the distribution of the different lipids (pixel size $15 \mu \mathrm{m}, 220 \times 185$ pixels)

in $\mathrm{ApoE}^{-/-}$but not in the WT mice. Lipid assignments are shown in Supplemental Table S3. In tissue sections of older $\mathrm{ApoE}^{-/-}$mice, the number of detected cholesterol esters was 4.8-fold higher than in those from WT mice and twofold higher than those from young $\mathrm{ApoE}^{-/-}$mice (Fig. 1a). The number of lysophosphatidylcholine (LPC)/lysophosphatidylethanolamine (LPE) lipids, representing most of the detected lipids, was found to be 1.5 -fold in tissue sections of older $\mathrm{ApoE}^{-/-}$mice as compared to WT or young $\mathrm{ApoE}^{-/-}$mice (Fig. 1a). For each considered lipid class, examples found to be significantly enriched in the aortic branch and carotid artery of the older $\mathrm{ApoE}^{-/-}$mice are shown in Fig. 1d-i and Supplemental Figure S2c-g, respectively.

The cholesterol derivative 7-ketocholesterol was detected exclusively in lipid-rich plaque regions in arteries branching off from the aortic arch of old $\mathrm{ApoE}^{-/-}$mice (Fig. 1e, Supplemental Figure S2c). Lysophosphatidylethanolamine LPE(22:0), the degradation product of phosphatidylethanolamine, was detected mainly in the plaque area of the brachiocephalic artery (BCA) (Fig. 1f) and of the right carotid artery (Supplemental Figure S2d). Lysophosphatidylcholine LPC(18:2) was located with the highest intensity in the plaque located at the root of the BCA but also in the whole vessel wall (Fig. 1g) which also held for the right carotid artery (Supplemental Figure S2e). Interestingly, the oxidized lipids 9(S)HODE CE (exemplarily shown in Fig. 1h and Supplemental Figure S2f) or oxCE (18:2), known to contribute to atherosclerosis progression [52], could be assigned to the $\mathrm{m} / \mathrm{z}$ value 687.56876. The cholesterol ester CE(20:4) was not increased in the core plaque area (Fig. 1i). Instead, it accumulated locally in the vessel wall at sites where presumably unidirectional shear stress is low or becomes oscillatory and preferably was located near the branch point and distal to the plaque (Fig. 1i and Supplemental Figure S2g). Statistical summaries of the intensities normalized to the total ion current (TIC) for these lipids in the arterial sections of wild-type, young, and old $\mathrm{ApoE}^{-1-}$ mice demonstrated significantly higher intensities in the analysed plaque area of the latter (Fig. 2a).

The (TIC) normalized intensities of the 65 signals detected in arterial specimens of the old $\mathrm{ApoE}^{-1-}$ mice were extracted from all MSI measurements done with the same specimens of young $\mathrm{ApoE}^{-/-}$or wild-type mice and subjected to principal component analysis (Fig. 2b). The cluster representing the older $\mathrm{ApoE}^{-/-}$mice (49-56 weeks,
ApoE1-4) was found to be separated from that of the young ApoE $^{-1-}$ mice (14-15 weeks, ApoE5,6) and age-matched wild-type mice (48-49 weeks, WT1-6). The lipid composition within the plaque areas of the young $\mathrm{ApoE}^{-/-}$mice was largely comparable to that of the wild-type mice.

\section{Human tissue samples}

The results of the human tissue measurements show a more diverse lipid distribution. In the direct comparison of the murine and human data, twenty six of the markers, which were exclusively identified in the vessel wall of the older $\mathrm{ApoE}^{-/-}$mice, were also detected in some of the human atherosclerotic plaque samples. Eight of the identified lipid markers, amongst them some cholesterol ester (18:2) and some lysophospholipid species, were also found in the human control samples (please refer to Supplemental Table S4). An exemplary image of a larger peripheral artery resected from the upper thigh (patient AT2, Fig. 3a) and the consecutive serial tissue sections with the marked MS image area is shown in Fig. 3b . Again, the detection of proinflammatory macrophages (Fig. 3a, insets 1-3) was used for the identification of the MS imaging region.

Some markers like cholesterol ester (18:2) or lysophosphatidylcholine (18:2), exemplarily shown for patient AT2 in Fig. $3 \mathrm{c}$ and e, that were exclusively found in the arterial specimens of the older $\mathrm{ApoE}^{-/-}$mice, could also be detected in human control samples. Interestingly, high intensities of the ester cholesteryl acetate (Fig. 3f) and the lysolipids LPE(18:0)/LPC(16:1) (Fig. 3d) were detected in macrophage-rich regions of the human atherosclerotic vessel wall (cf. Figure 3A, inset 1).

In an extensive data analysis without marker preselection based on mouse data, in total, $317 \mathrm{~m} / z$ values were found in all human tissue samples and subjected to supervised principal component analysis. Samples were divided into the group with atherosclerotic arteries (AT) and tissue with no significant pathological findings (control). The list of $317 \mathrm{~m} / z$ values was reduced by the prerequisite that the considered $m / z$ value must be detected in $70 \%$ of the samples of at least one group. PCA of the remaining $25 \mathrm{~m} / z$ values shows a clear separation between the control and atherosclerotic tissue samples (Fig. 4a). Seven of these $m / z$ values can be considered statistically significant atherosclerotic tissue markers; one species shows at least a trend towards significance (Supplemental Table S5). Amongst these, the lysophosphatidylcholine species $\operatorname{LPC}(22: 5)$ and $\operatorname{LPC}(22: 6)$ have already been identified as markers for the older atherosclerotic $\mathrm{ApoE}^{-/-}$mice (Fig. 5). Four glucosylated cholesterol species, the esterified acyl steryl glucosides 16:0, 16:3, 18:3, and 22:0, not being detected in the murine atherosclerotic tissue, were identified as statistically significant human atherosclerotic markers (Fig. 5, Supplemental Figure S3). 
Additionally, a significant difference in the lipid composition of patients receiving lipid-lowering drugs compared to patients without a comparable medication was detected (Fig. 4b). The analysed tissue samples of the five patients receiving an HMG-CoA reductase inhibitor showed significantly lower amounts of cholesterol derivatives (CDs) due to the cholesterol-lowering effect of the drugs as compared to patients receiving no such treatment.

\section{Discussion}

The atherosclerosis-prone $\mathrm{ApoE}^{-/-}$mouse is one of the most widely used murine models for the study of atherosclerosis [15]. The lesion distribution in these mice is similar to humans, with a predominance in the aortic root, carotid artery, and other branches of the aorta [39], so that initiation and progression of plaque formation have been extensively studied in these mice [54]. This monogenetic murine model has also been widely used with high reproducibility to identify metabolic oxidative stress markers in the context of cardiovascular disease [11]. Despite the accelerated atherosclerosis development, a major limitation of the $\mathrm{ApoE}^{-/-}$mouse model is that the lesions rarely rupture and hence do not lead to thrombosis, whereas vascular occlusion is common in humans [39]. In our study, we used MALDI MSI for the direct comparison of murine and human atherosclerotic plaques to determine universally applicable atherosclerotic plaque biomarkers. In addition, a separate data analysis of the human MSI data was performed to determine markers for human atherosclerotic samples.

Using principal component analysis, we found two distinguishable clusters between matching arterial vessel specimens of older $\mathrm{ApoE}^{-/-}$mice and age-matched wildtype littermate control animals. The young $\mathrm{ApoE}^{-/-}$mice showed a lipid composition more comparable to that of the wild-type mice. When getting older, the increase in the severity of hypercholesterolemia and plasma CE levels plays critical roles in the pathogenesis of atherosclerosis in these animals, as it alters the cellular lipid composition like
Fig. 4 Statistical Analysis of human tissue data. a Principal component analysis of $25 \mathrm{~m} / z$ values found in $70 \%$ of the control group (C1-3) and/or the group with atherosclerotic arteries (AT1-8) showing a clear separation between the two groups. b Effect of statin therapy on the number of lipids detected in the analysed human tissue samples. Control tissue $(n=3)$, plaque tissue from patients without $(n=3)$, and with HMG-CoA reductase inhibitor treatment $(n=5)$. $* p<0.05$ w/o statins vs. control or drug therapy

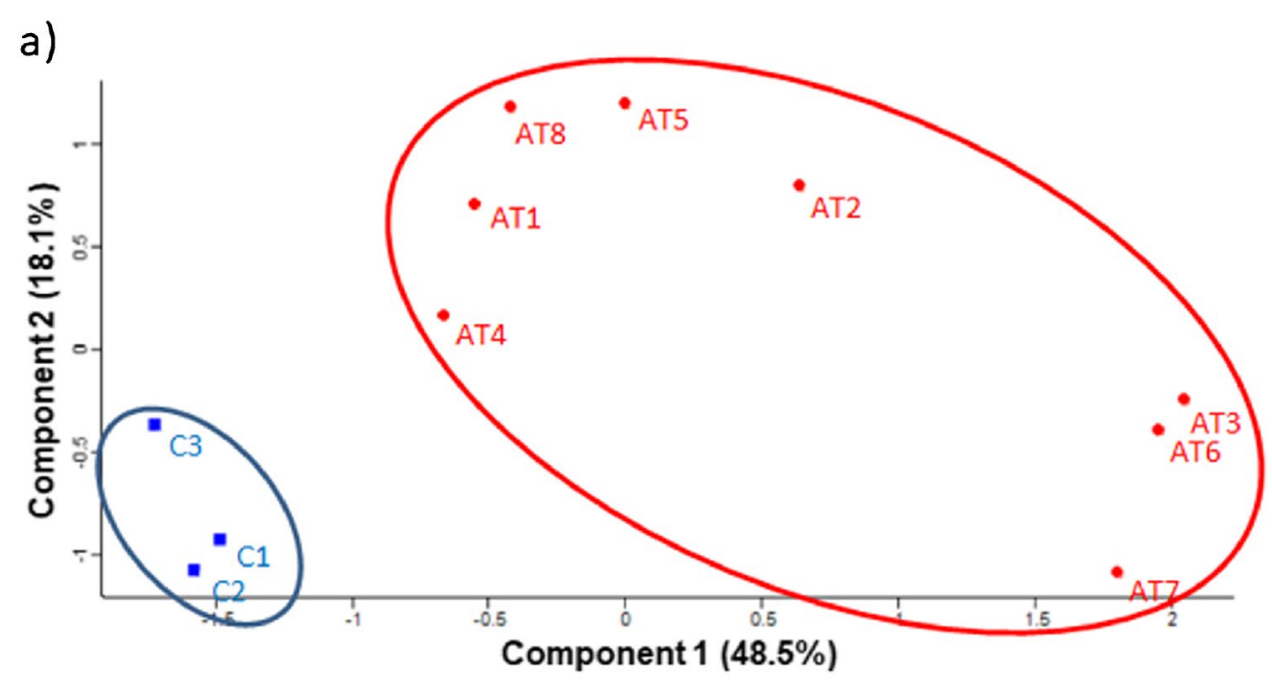

b)
CE

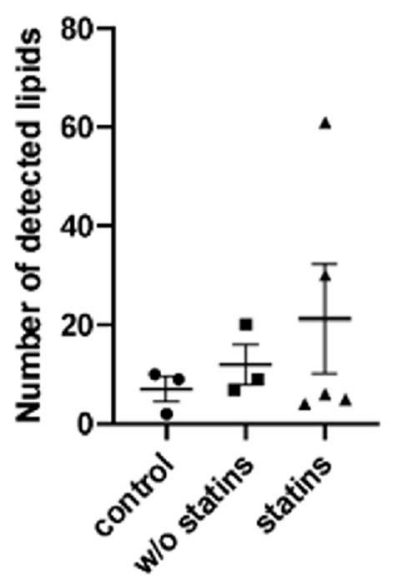

LPC/LPE

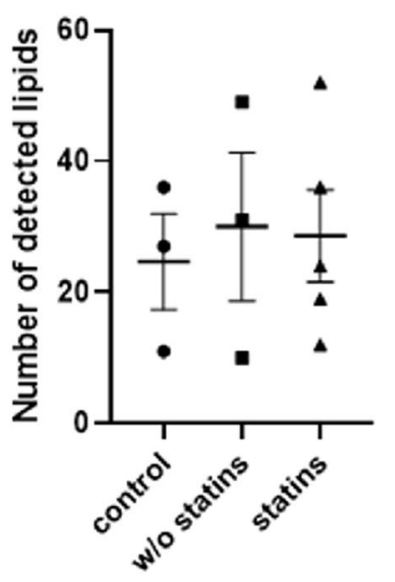

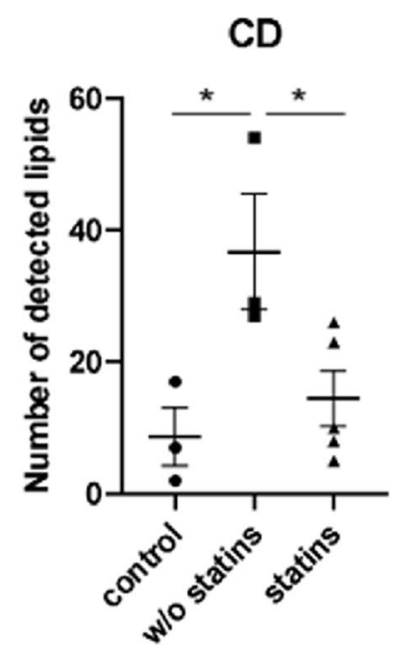


it has been described recently for the development of an impaired skin barrier function in the same mouse model [34]. Very recently, a total of 25 aortic plaque-specific lipid species have been identified by comparing LDLR $^{-/-}$and $\mathrm{ApoE}^{-/-}$mice fed a high-fat diet for 16 weeks using MALDI MSI. Tissue from wild-type C57BL/6 mice was not analysed but 11 lipid species were consistently detected in atherosclerotic plaques of both mouse strain [6]. Fourteen of these 25 lipids were also identified in our analyses (see Supplemental Table S3). Interestingly, LPE(22:0) specific for atherosclerotic $\mathrm{ApoE}^{-/-}$mice in our study is positively associated with stable coronary artery disease evaluated by plasma lipidomic analysis [35]. Cholesterol ester CE(18:2), additionally identified in our study as ApoE-specific plaque biomarker, was also previously detected in aortic roots of $\mathrm{ApoE}^{-/-}$mice at 60 weeks of age and in femoral arteries of humans with peripheral artery occlusive disease using MSI [56]. The accumulation of cholesterol ester in the arterial intima is one of the main characteristics of macrophage foam cells that reinforce the development of atherosclerotic plaques [16].

9-HODE, the stable oxidation product of linoleic acid in $\mathrm{CE}$, is also known to contribute to the progression of atherosclerosis and the risk of clinical events such as myocardial infarction or stroke [52]. In this late stage of atherosclerosis, the nonenzymatically generated pro-inflammatory
9-HODE increased apoptosis leading to a fragile, acellular plaque [52]. 7-Ketocholestrol, another identified oxysterol in our study, is believed to play an important role in plaque development as it has more potent pro-atherogenic effects than cholesterol [49]. All other lipid species, in addition to the 31 selected in our study, could also be detected in wildtype mice and therefore do not represent specific MALDI MSI detectable lipid biomarkers for atherosclerosis, even though lysophospholipids are known to be involved in the development and progression of the disease [30].

Unfortunately, under the given conditions, a quantitative statistical analysis for lipids in individual layers of the vessel was not possible. So far, only a few studies using MALDI MSI analysis of human arteries have been published (summarized in [41]). The lysophosphatidylcholine species $\operatorname{LPC}(22: 5)$ and $\operatorname{LPC}(22: 6)$ were exclusively identified in the older $\mathrm{ApoE}^{-/-}$mice and were also identified as a human atherosclerotic tissue marker. LysoPCs are products of phospholipase A2 (PLA2) enzyme activity [10]. High lysophospholipid content destabilizes membranes. Lipoprotein-associated PLA2 levels have been described to be associated with stroke and atherosclerosis [23]. Some of these presumably specific atherosclerotic markers identified in the older $\mathrm{ApoE}^{-1-}$ mice like cholesterol ester (18:2) and lysophospholipid species were also found in human control samples. This illustrates that the human vascular specimens
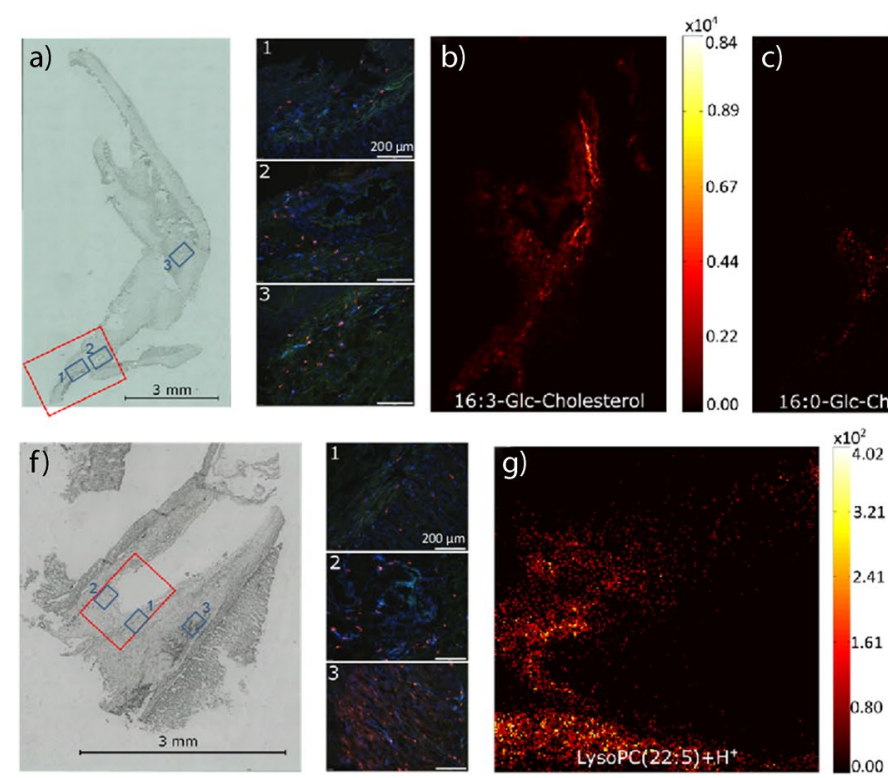

Fig. 5 Human atherosclerotic tissue marker. Exemplary presentation of resected lower leg peripheral arteries with arteriosclerotic changes of patient AT6 and AT7. a Optical image depicting macrophage infiltrates (red fluorescence) into the atherosclerotic vessel wall (refer to insets 1-3, marked as blue squares in the optical image). The red square shows the area which was measured with MALDI MSI (pixel size $15 \mu \mathrm{m}, 220 \times 185$ pixels). Exemplary artery MS image of patient AT6 show the marker b 16:3-Glc-Cholesterol, c 16:0-Glc-Cholesterol, d 18:3-Glc-Cholesterol, and e 22:0-GlcCholesterol (pixel size $7 \mu \mathrm{m}, 220 \times 350$ pixels). f Optical image of the vessel resection of patient AT7 with marked macrophage infiltrates (blue squares 1-3) and the measured MALDI MSI area (red square). Exemplary MS images of the lysophosphatidylcholine marker show g LysoPC(22:5) $+\mathrm{H}^{+}$, h LysoPC(22:6), and i LysoPC(22:5) $+\mathrm{Na}^{+}$ (pixel size $5 \mu \mathrm{m}, 200 \times 200$ pixels) 
show a more diverse patient-dependent lipid distribution, which is at variance with the vascular specimens derived from the monogenetic $\mathrm{ApoE}^{-/-}$mice. However, it confirms previous findings that clinically relevant atherosclerotic plaques contain a variable mix of lipids [2]. This may be since different stages of atherosclerosis progression lead to larger differences in their lipid profiles. Moreover, diet and lifestyle, i.e., a diet rich in fat and sugar, and smoking [5], as well medication of the patients with cholesterol-lowering drugs [9] influence the lipid profile and hence the results.

However, based on a principal component analysis, we were able to identify four more statistically significant atherosclerotic tissue markers in the human data set which fulfil the prerequisite of being detected in more than $70 \%$ of the samples of the atherosclerotic patient group. To the best of our knowledge, these acetylated colesterylsteryl glucosides which belong to the group of sterol lipids are sterol derivatives that have not been described in the context of atherosclerosis before. They belong to the complex group of glycolipids or steryl glycosides and are common plant phytosterol lipids [37] but also have been relatively recently found in various human tissues in significant amounts [4]. Here they serve, e.g., as storage forms of sterols but are also important for the physical stability of the cell membrane [17]. Interestingly, acyl steryl glucosides have been found to stimulate macrophages [48]. Moreover, the supposed acyltransferases involved in the biosynthesis of steryl acyl glucosides require exogenous acyl lipids such as glycerophospholipids as fatty acid sources for acylation [48]. This might explain the observed high content of lysophospholipids destabilizing cellular membranes. On the other hand, it is also possible that glycated lipids accumulated to significant extents in the cells may not be detoxified through the actions of glyoxalase 1 [32]. In our study, colesterylsteryl acyl glucosides could almost be exclusively detected in human atherosclerotic tissue. In this context, it is important to note that higher levels of glycated lipids as advanced glycation end products (AGEs) were associated with a plaque rupture phenotype, typically not observed in mouse models [32].

Additionally, within the human samples, a significantly lower number of cholesterol derivatives, like oxysterols, were detected in vessels of patients receiving HMG-CoA reductase inhibitor treatment. Oxysterols are major constituents of oxLD involved in the pathogenesis of atherosclerotic lesion formation through cholesterol accumulation in macrophage or vascular smooth muscle cell-derived foam cells [29]. HMG-CoA reductase inhibitors also potently inhibit the primary cellular acyl-CoA: cholesterol O-acyltransferase (ACAT) isoform 1, thereby inhibiting esterification of cholesterol and ultimately reducing the accumulation and number of lipid species in the foam cell [3].

The imaged human atherosclerotic vessels in our study originate from amputated limbs. It must also be considered that the human control tissue samples were, of course, free from atherosclerotic changes but originate from amputations due to an injury or disease which of course could influence the immune response leading to differences in the vessel microenvironment and subsequently lipid composition. Therefore, it is not surprising that some of the identified human atherosclerotic tissue markers were also detected in the human control samples.

In summary, our study identified several atherosclerosisspecific lipid biomarkers but demonstrated that a comparison between atherosclerotic vessels originating from a monogenetic mouse model and humans with differences in genetic background, diet, and lifestyle is rather difficult and may lead to wrong conclusions. Signal intensities of less abundant lipids in high spatial resolution MSI experiments are often quite low, making this approach difficult and timeconsuming especially since this analysis must be performed on every lipid species. Therefore, the lipid species in this study could only be assigned (to one or more lipids) but not unequivocally identified. We nonetheless show that highresolution MALDI mass spectrometry imaging is a valid method to comprehensively investigate the lipid profile of atherosclerotic plaques derived from both mice and men.

Supplementary Information The online version contains supplementary material available at https://doi.org/10.1007/s00424-021-02643-x.

Acknowledgements We are grateful for the expert technical assistance and help provided by Nadine Heselmaier and Franziska Mohr. Financial support by the Deutsche Forschungsgemeinschaft (CRC Transregio 23 subproject C6, CRC 1118 subproject S02 and grant Sp314/13-1) is gratefully acknowledged.

Author contribution P. K.-S., B. S., S. S., M. H., and A. H. W. wrote the manuscript. P. K.-S., S. G., N. V., and A. H. W. designed the experiments. P. K.-S. and A. H. W. performed the experiments and analysed the data. All authors read the manuscript and provided critical input.

Funding Open Access funding enabled and organized by Projekt DEAL.

\section{Declarations}

Conflict of interest B. S. is a consultant of TransMIT GmbH, Giessen, Germany. The other authors declare no conflicts of interest.

Open Access This article is licensed under a Creative Commons Attribution 4.0 International License, which permits use, sharing, adaptation, distribution and reproduction in any medium or format, as long as you give appropriate credit to the original author(s) and the source, provide a link to the Creative Commons licence, and indicate if changes were made. The images or other third party material in this article are included in the article's Creative Commons licence, unless indicated otherwise in a credit line to the material. If material is not included in the article's Creative Commons licence and your intended use is not permitted by statutory regulation or exceeds the permitted use, you will need to obtain permission directly from the copyright holder. To view a copy of this licence, visit http://creativecommons.org/licenses/by/4.0/. 


\section{References}

1. Abe A, Hiraoka M, Ohguro H, Tesmer JJ, Shayman JA (2017) Preferential hydrolysis of truncated oxidized glycerophospholipids by lysosomal phospholipase A2. J Lipid Res 58:339-349. https:// doi.org/10.1194/jlr.M070730

2. Andersson M, Groseclose MR, Deutch AY, Caprioli RM (2008) Imaging mass spectrometry of proteins and peptides: $3 \mathrm{D}$ volume reconstruction. Nat Methods 5:101-108. https://doi.org/10.1038/ nmeth1145

3. Bagheri B, Alikhani A, Mokhtari H, Rasouli M (2018) Esterification of HDL-cholesterol is decreased in diabetes mellitus and $\mathrm{CAD}$ and enhanced following treatment with statins. Med Arch 72:197-201. https://doi.org/10.5455/medarh.2018.72.197-201

4. Boer DEC, Mirzaian M, Ferraz MJ, Nadaban A, Schreuder A, Hovnanian A, van Smeden J, Bouwstra JA, Aerts J (2020) Glucosylated cholesterol in skin: synthetic role of extracellular glucocerebrosidase. Clin Chim Acta 510:707-710. https://doi.org/10. 1016/j.cca.2020.09.017

5. Buttar HS, Li T, Ravi N (2005) Prevention of cardiovascular diseases: role of exercise, dietary interventions, obesity and smoking cessation. Exp Clin Cardiol 10:229-249

6. Cao J, Goossens P, Martin-Lorenzo M, Dewez F, Claes BSR, Biessen EAL, Heeren RMA, Balluff B (2020) Atheroma-specific lipids in $\operatorname{ldlr}(-/-)$ and apoe(-/-) mice using $2 \mathrm{D}$ and 3D matrixassisted laser desorption/ionization mass spectrometry imaging. J Am Soc Mass Spectrom 31:1825-1832. https://doi.org/10.1021/ jasms.0c00070

7. Castro-Perez J, Hatcher N, Kofi Karikari N, Wang SP, Mendoza V, Shion H, Millar A, Shockcor J, Towers M, McLaren D, Shah V, Previs S, Akinsanya K, Cleary M, Roddy TP, Johns DG (2014) In vivo isotopically labeled atherosclerotic aorta plaques in ApoE $\mathrm{KO}$ mice and molecular profiling by matrix-assisted laser desorption/ionization mass spectrometric imaging. Rapid Commun Mass Spectrom 28:2471-2479. https://doi.org/10.1002/rcm.7039

8. Choi SH, Sviridov D, Miller YI (2017) Oxidized cholesteryl esters and inflammation. Biochim Biophys Acta Mol Cell Biol Lipids 1862:393-397. https://doi.org/10.1016/j.bbalip.2016.06.020

9. Chou R, Dana T, Blazina I, Daeges M, Jeanne TL (2016) Statins for prevention of cardiovascular disease in adults: evidence report and systematic review for the US Preventive Services Task Force. JAMA 316:2008-2024. https://doi.org/10.1001/jama.2015.15629

10. Cunningham TJ, Yao L, Lucena A (2008) Product inhibition of secreted phospholipase A2 may explain lysophosphatidylcholines' unexpected therapeutic properties. J Inflamm (Lond) 5:17. https:// doi.org/10.1186/1476-9255-5-17

11. Dinh QN, Chrissobolis S, Diep H, Chan CT, Ferens D, Drummond GR, Sobey CG (2017) Advanced atherosclerosis is associated with inflammation, vascular dysfunction and oxidative stress, but not hypertension. Pharmacol Res 116:70-76. https://doi.org/ 10.1016/j.phrs.2016.12.032

12. Fahy E, Subramaniam S, Murphy RC, Nishijima M, Raetz CR, Shimizu T, Spener F, van Meer G, Wakelam MJ, Dennis EA (2009) Update of the LIPID MAPS comprehensive classification system for lipids. J Lipid Res 50(Suppl):S9-14. https://doi.org/10. 1194/jlr.R800095-JLR200

13. Gargiulo S, Testa G, Gamba P, Staurenghi E, Poli G, Leonarduzzi G (2017) Oxysterols and 4-hydroxy-2-nonenal contribute to atherosclerotic plaque destabilization. Free Radic Biol Med 111:140-150. https://doi.org/10.1016/j.freeradbiomed.2016.12. 037

14. Garikapati V, Karnati S, Bhandari DR, Baumgart-Vogt E, Spengler B (2019) High-resolution atmospheric-pressure MALDI mass spectrometry imaging workflow for lipidomic analysis of late fetal mouse lungs. Sci Rep 9:3192. https://doi.org/10.1038/ s41598-019-39452-3

15. Getz GS, Reardon CA (2012) Animal models of atherosclerosis. Arterioscler Thromb Vasc Biol 32:1104-1115. https://doi.org/10. 1161/atvbaha.111.237693

16. Ghosh S, Zhao B, Bie J, Song J (2010) Macrophage cholesteryl ester mobilization and atherosclerosis. Vascul Pharmacol 52:1-10. https://doi.org/10.1016/j.vph.2009.10.002

17. Grille S, Zaslawski A, Thiele S, Plat J, Warnecke D (2010) The functions of steryl glycosides come to those who wait: recent advances in plants, fungi, bacteria and animals. Prog Lipid Res 49:262-288. https://doi.org/10.1016/j.plipres.2010.02.001

18. Gutstein DE, Fuster V (1999) Pathophysiology and clinical significance of atherosclerotic plaque rupture. Cardiovasc Res 41:323-333. https://doi.org/10.1016/s0008-6363(98)00322-8

19. Hasanally D, Edel A, Chaudhary R, Ravandi A (2017) Identification of oxidized phosphatidylinositols present in OxLDL and human atherosclerotic plaque. Lipids 52:11-26. https://doi.org/ 10.1007/s11745-016-4217-y

20. Huber K, Khamehgir-Silz P, Schramm T, Gorshkov V, Spengler B, Römpp A (2018) Approaching cellular resolution and reliable identification in mass spectrometry imaging of tryptic peptides. Anal Bioanal Chem 410:5825-5837. https://doi.org/10.1007/ s00216-018-1199-z

21. Hutchins PM, Moore EE, Murphy RC (2011) Electrospray MS/ MS reveals extensive and nonspecific oxidation of cholesterol esters in human peripheral vascular lesions. J Lipid Res 52:20702083. https://doi.org/10.1194/jlr.M019174

22. Kadesch P, Quack T, Gerbig S, Grevelding CG, Spengler B (2019) Lipid topography in schistosoma mansoni cryosections, revealed by microembedding and high-resolution atmospheric-pressure matrix-assisted laser desorption/ionization (MALDI) mass spectrometry imaging. Anal Chem 91:4520-4528. https://doi.org/10. 1021/acs.analchem.8b05440

23. Katan M, Moon YP, Paik MC, Wolfert RL, Sacco RL, Elkind MS (2014) Lipoprotein-associated phospholipase A2 is associated with atherosclerotic stroke risk: the Northern Manhattan Study. PLoS ONE 9:e83393. https://doi.org/10.1371/journal.pone.00833 93

24. Khalil SM, Römpp A, Pretzel J, Becker K, Spengler B (2015) Phospholipid Topography of whole-body sections of the anopheles stephensi mosquito, characterized by high-resolution atmospheric-pressure scanning microprobe matrix-assisted laser desorption/ionization mass spectrometry imaging. Anal Chem 87:11309-11316. https://doi.org/10.1021/acs.analchem.5b02781

25. Kompauer M, Heiles S, Spengler B (2017) Atmospheric pressure MALDI mass spectrometry imaging of tissues and cells at $1.4-\mu \mathrm{m}$ lateral resolution. Nat Methods 14:90-96. https://doi.org/10.1038/ nmeth.4071

26. Kompauer M, Heiles S, Spengler B (2017) Autofocusing MALDI mass spectrometry imaging of tissue sections and 3D chemical topography of nonflat surfaces. Nat Methods 14:1156-1158. https://doi.org/10.1038/nmeth.4433

27. Lee JW, Mok HJ, Lee DY, Park SC, Kim GS, Lee SE, Lee YS, Kim KP, Kim HD (2017) UPLC-QqQ/MS-based lipidomics approach to characterize lipid alterations in inflammatory macrophages. J Proteome Res 16:1460-1469. https://doi.org/10.1021/ acs.jproteome.6b00848

28. Li YF, Li RS, Samuel SB, Cueto R, Li XY, Wang H, Yang XF (2016) Lysophospholipids and their G protein-coupled receptors in atherosclerosis. Front Biosci (Landmark Ed) 21:70-88. https:// doi.org/10.2741/4377

29. Lin HC, Lii CK, Chen HC, Lin AH, Yang YC, Chen HW (2018) Andrographolide Inhibits oxidized LDL-induced cholesterol 
accumulation and foam cell formation in macrophages. Am J Chin Med 46:87-106. https://doi.org/10.1142/s0192415x18500052

30. Liu P, Zhu W, Chen C, Yan B, Zhu L, Chen X, Peng C (2020) The mechanisms of lysophosphatidylcholine in the development of diseases. Life Sci 247:117443. https://doi.org/10.1016/j.lfs.2020. 117443

31. Lohofer F, Buchholz R, Glinzer A, Huber K, Haas H, Kaissis G, Feuchtinger A, Aichler M, Sporns PB, Holtke C, Stolting M, Schilling F, Botnar RM, Kimm MA, Faber C, Walch AK, Zernecke A, Karst U, Wildgruber M (2020) Mass spectrometry imaging of atherosclerosis-affine gadofluorine following magnetic resonance imaging. Sci Rep 10:79. https://doi.org/10.1038/ s41598-019-57075-6

32. López-Díez R, Shekhtman A, Ramasamy R, Schmidt AM (2016) Cellular mechanisms and consequences of glycation in atherosclerosis and obesity. Biochim Biophys Acta 1862:2244-2252. https:// doi.org/10.1016/j.bbadis.2016.05.005

33. Martinez E, Martorell J, Riambau V (2020) Review of serum biomarkers in carotid atherosclerosis. J Vasc Surg 71:329-341. https://doi.org/10.1016/j.jvs.2019.04.488

34. Martins Cardoso R, Creemers E, Absalah S, Gooris GS, Hoekstra M, Van Eck M, Bouwstra JA (2019) Hypercholesterolemia in young adult APOE(-/-) mice alters epidermal lipid composition and impairs barrier function. Biochim Biophys Acta Mol Cell Biol Lipids 1864:976-984. https://doi.org/10.1016/j.bbalip.2019.03. 008

35. Meikle PJ, Wong G, Tsorotes D, Barlow CK, Weir JM, Christopher MJ, MacIntosh GL, Goudey B, Stern L, Kowalczyk A, Haviv I, White AJ, Dart AM, Duffy SJ, Jennings GL, Kingwell BA (2011) Plasma lipidomic analysis of stable and unstable coronary artery disease. Arterioscler Thromb Vasc Biol 31:2723-2732. https://doi.org/10.1161/atvbaha.111.234096

36. Miller YI, Shyy JY (2017) Context-dependent role of oxidized lipids and lipoproteins in inflammation. Trends Endocrinol Metab 28:143-152. https://doi.org/10.1016/j.tem.2016.11.002

37. Murai T, Jin S, Itoh M, Horie Y, Higashi T, Ikegawa S (2020) Analysis of steryl glucosides in rice bran-based fermented food by LC/ESI-MS/MS. Steroids 158:108605. https://doi.org/10.1016/j. steroids.2020.108605

38. Nakazawa G, Yazdani SK, Finn AV, Vorpahl M, Kolodgie FD, Virmani R (2010) Pathological findings at bifurcation lesions: the impact of flow distribution on atherosclerosis and arterial healing after stent implantation. J Am Coll Cardiol 55:1679-1687. https:// doi.org/10.1016/j.jacc.2010.01.021

39. Oppi S, Lüscher TF, Stein S (2019) Mouse models for atherosclerosis research-which is my line? Front Cardiovasc Med 6:46. https://doi.org/10.3389/fcvm.2019.00046

40. Paschke C, Leisner A, Hester A, Maass K, Guenther S, Bouschen W, Spengler B (2013) Mirion-a software package for automatic processing of mass spectrometric images. J Am Soc Mass Spectrom 24:1296-1306. https://doi.org/10.1007/s13361-013-0667-0

41. Patterson NH, Doonan RJ, Daskalopoulou SS, Dufresne M, Lenglet S, Montecucco F, Thomas A, Chaurand P (2016) Threedimensional imaging MS of lipids in atherosclerotic plaques: open-source methods for reconstruction and analysis. Proteomics 16:1642-1651. https://doi.org/10.1002/pmic.201500490

42. Ravandi A, Leibundgut G, Hung MY, Patel M, Hutchins PM, Murphy RC, Prasad A, Mahmud E, Miller YI, Dennis EA, Witztum JL, Tsimikas S (2014) Release and capture of bioactive oxidized phospholipids and oxidized cholesteryl esters during percutaneous coronary and peripheral arterial interventions in humans. J Am Coll Cardiol 63:1961-1971. https://doi.org/10.1016/j.jacc. 2014.01.055

43. Reis A (2017) Oxidative Phospholipidomics in health and disease: achievements, challenges and hopes. Free Radic Biol Med 111:25-37. https://doi.org/10.1016/j.freeradbiomed.2017.01.014
44. Robichaud G, Barry JA, Garrard KP, Muddiman DC (2013) Infrared matrix-assisted laser desorption electrospray ionization (IR-MALDESI) imaging source coupled to a FT-ICR mass spectrometer. J Am Soc Mass Spectrom 24:92-100. https://doi.org/10. 1007/s13361-012-0505-9

45. Rompp A, Guenther S, Schober Y, Schulz O, Takats Z, Kummer W, Spengler B (2010) Histology by mass spectrometry: label-free tissue characterization obtained from high-accuracy bioanalytical imaging. Angew Chem Int Ed Eng1 49:3834-3838. https://doi.org/ 10.1002/anie.200905559

46. Ross R (1999) Atherosclerosis - an inflammatory disease. N Engl J Med 340:115-126. https://doi.org/10.1056/nejm19990114340 0207

47. Schulz S, Becker M, Groseclose MR, Schadt S, Hopf C (2019) Advanced MALDI mass spectrometry imaging in pharmaceutical research and drug development. Curr Opin Biotechnol 55:51-59. https://doi.org/10.1016/j.copbio.2018.08.003

48. Shimamura M (2020) Structure, metabolism and biological functions of steryl glycosides in mammals. Biochem J 477:4243-4261. https://doi.org/10.1042/bcj20200532

49. Son Y, Kim K, Kim S, Lee SA, Jang H, Rhim BY (2012) Roles of 7-ketocholesterol on the homeostasis of intracellular cholesterol level. J Cardiovasc Pharmacol 60:199-207. https://doi.org/10. 1097/FJC.0b013e31825c3ddc

50. Spengler B, Hubert M, Kaufmann R (1994) Proceedings of the 42nd ASMS conference on mass spectrometry and allied topics. Chicago, IL (United States), 29 May - 3 Jun 1994. MALDI ion imaging and biological ion imaging with a new scanning UV-laser microprobe. ASMS, East Lansing, MI (United States),

51. Stegemann C, Drozdov I, Shalhoub J, Humphries J, Ladroue C, Didangelos A, Baumert M, Allen M, Davies AH, Monaco C, Smith A, Xu Q, Mayr M (2011) Comparative lipidomics profiling of human atherosclerotic plaques. Circ Cardiovasc Genet 4:232-242. https://doi.org/10.1161/circgenetics.110.959098

52. Vangaveti V, Baune BT, Kennedy RL (2010) Hydroxyoctadecadienoic acids: novel regulators of macrophage differentiation and atherogenesis. Ther Adv Endocrinol Metab 1:51-60. https://doi. org/10.1177/2042018810375656

53. Visscher M, Moerman AM, Burgers PC, Van Beusekom HMM, Luider TM, Verhagen HJM, Van der Steen AFW, Van der Heiden K, Van Soest G (2019) Data processing pipeline for lipid profiling of carotid atherosclerotic plaque with mass spectrometry imaging. J Am Soc Mass Spectrom 30:1790-1800. https://doi.org/10.1007/ s13361-019-02254-y

54. Whitman SC (2004) A practical approach to using mice in atherosclerosis research. Clin Biochem Rev 25:81-93

55. World Health Organization cardiovascular disease risk charts (2019) revised models to estimate risk in 21 global regions. Lancet Glob Health 7:e1332-e1345. https://doi.org/10.1016/s2214109x(19)30318-3

56. Zaima N, Sasaki T, Tanaka H, Cheng XW, Onoue K, Hayasaka T, Goto-Inoue N, Enomoto H, Unno N, Kuzuya M, Setou M (2011) Imaging mass spectrometry-based histopathologic examination of atherosclerotic lesions. Atherosclerosis 217:427-432. https://doi. org/10.1016/j.atherosclerosis.2011.03.044

Publisher's note Springer Nature remains neutral with regard to jurisdictional claims in published maps and institutional affiliations. 